International Journal of Engineering \& Technology, 7 (4.44) (2018) 127-130
International Journal of Engineering \& Technology
WPC
Website: $w$ ww.sciencepubco.com/index.php/IJET
Research paper

\title{
Implementation of missed call for making a password and controlling devices
}

\author{
Ferry Wahyu Wibowo ${ }^{1 *}$ \\ ${ }^{1}$ Informatics Department, Universitas Amikom Yogyakarta \\ *Corresponding author E-mail: ferry.w@amikom.ac.id
}

\begin{abstract}
The cellular phones do not use telephone cables. The cellular phones send radio signals into the air to the nearest transmitter tower called the base station. The transmitter tower will emit the signal to the next station and so on until it reaches the phone that is called. When a new call arrives on the phone number, it will generate a tone until it is picked up, rejected, or the time has been ended to receive this tone (each telephone network provider has different policies related to the time used for this telephone connection so that this causes the number of rings raised to vary). This paper focuses on the missed call services which is one of the features found on the telephone. The tone that has been generated by this calling can emerge ring. This ring can be detected and manipulated to be something useful for controlling devices or making some password.
\end{abstract}

Keywords: Control, Missed call, Password, Ring, Telephone.

\section{Introduction}

The communication data is a field that has an intersection between the field of communication and information technology. The comprising of the information technology has a wide contribution to the human life while the communication in the worldwide has a portion to share the information and make a network. The technology has a rapid innovation with the development of the devices, products, and theories. This also has an impact on the other sectors. The industrial revolution has also grown more over to balance with the rising of the knowledge [1]. Many applications could be categorized into some definitions. The categories of the human-machine interaction (HCI) has 3 definitions which are the interaction between person and person, the interaction between person and machine, and the interaction between machine and machine.

This paper addressed the control system which is emphasizing on utilizing of the cellular phone services i.e. missed call service. A missed calling is one of the features of the telephone that for some people perhaps it could annoy but for others, it could be utilized, it depends on the condition and usage. The missed call is an activity to call a number of the mobile phone/cellular phone and hang up before that mobile phone number can pick up the call. It could be meaning if there is a commitment before such as requesting to call back, picking up now, etc. [2]. The missed call is an intentional use by older mobile phone users and it also could be known with another term as deliberately missed call (DMC) [3]. The missed call is no charge communication, but it could be charged by the provider if the user intends to miss call to such number of mobile phones but it gets the answer by the provider. At the beginning of the emerging, this feature of the mobile phone in some countries has been widely used and spread. The mechanism of the mobile phones works can be written as following when the sender dials the mobile phone numbers and thus press the call key. The mobile phone will select the available radio channels and sends a radio signal containing a mobile phone/telephone numbers that will be called to the nearest base station. So then the base station will send a signal to the nearest base station network until it finds the phone that is called. The phone that is called sends a message back through the base station, which states whether the phone is available or not. At that time, it can be heard the dial tone. This will continue until the telephone is picked up or disconnected by the recipient. The dial tone sound has a number that varies from one provider to another provider. The amount of information that can be sent by the modem is limited by its speed in processing information. The data compression can speed up the process by cutting up information that is not important. The amount of information that can be processed every second by a telephone is called the bandwidth.

\section{AT Commands}

One of the control commands of the cellular phone modulator/demodulator (modem) is known as an AT command. The AT itself is an abbreviation of Attention [4]. Every command to control the modem starts with "AT" so that's why it is called AT commands e.g. ATA (used to answer), ATD (used to dial), ATH (used to hook control), and ATO (used to return to online data). So the command of "AT" is the prefix that instructs the modem to do something or specific tasks. These command sets are supported by the general packet radio service (GPRS) / global system for mobile communication (GSM), besides for the modems, the mobile phones are also supporting these command sets with the specific to the technology of GSM e.g. AT+CMGL (used to list short message service (SMS)), AT+CMGR (used to read an SMS messages), AT+CMGS (used to send SMS message), and AT+CMSS (used to send SMS message from the storage). From this definition, it could be withdrawn a conclusion of the categories which are basic commands and extended commands. The first example mentioned is categorized as basic commands while the second example is 
categorized as extended commands. This AT command is using a conversion from the text to the format of a protocol data unit (PDU) code and otherwise. In sending or receiving the short message service (SMS), there are two modes i.e. a text mode and PDU mode. For some text mode, it is unavailable on some cellular phones. It is the only encoding of the bit stream data represented by the PDU mode. Many encoding alternatives that can be implemented when it is displayed on the cellular phone as an SMS message but the cellular phone will select the proper encoding. The lack of the use of the text mode is of this mode limited by the set of preset encoding options while if the PDU mode is chosen, any encoding can be implemented. The PDU contains the hexadecimal numbers and has some headers. The tool to make a conversion of the PDU code could be employed the software of PDU spy as shown in Figure 1.

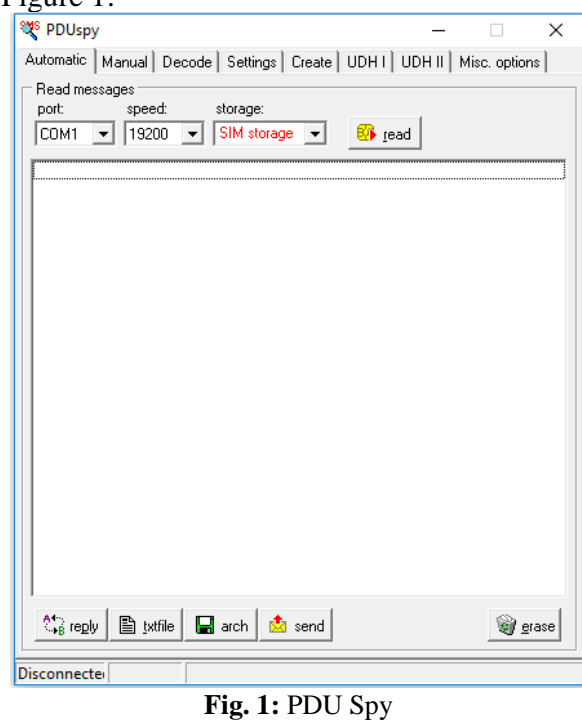

While for its conversion, it is applying Implementation of the 7-bit schema as shown in Table 1 .

Table 1: 7-bit schema

\begin{tabular}{|c|c|c|c|c|c|c|c|c|c|c|c|c|}
\hline & & & & & 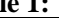 & OTh & 1 & & & & & \\
\hline & & & & b 7 & 0 & 0 & 0 & 0 & 1 & 1 & 1 & 1 \\
\hline & & & & b 6 & 0 & 0 & 1 & 1 & 0 & 0 & 1 & 1 \\
\hline & & & & b 5 & 0 & 1 & 0 & 1 & 0 & 1 & 0 & 1 \\
\hline b 4 & b 3 & b 2 & b 1 & & 0 & 1 & 2 & 3 & 4 & 5 & 6 & 7 \\
\hline 0 & 0 & 0 & 0 & 0 & @ & $\Delta$ & $\mathrm{SP}$ & 0 & - & $\mathrm{P}$ & $\cdots$ & $\mathrm{p}$ \\
\hline 0 & 0 & 0 & 1 & 1 & & & $!$ & 1 & $\mathrm{~A}$ & $\mathrm{Q}$ & $\mathrm{a}$ & $\mathrm{q}$ \\
\hline 0 & 0 & 1 & 0 & 2 & $\$$ & $\Phi$ & “ & 2 & B & $\mathrm{R}$ & $\mathrm{b}$ & $r$ \\
\hline 0 & 0 & 1 & 1 & 3 & & $\Gamma$ & \# & 3 & $\mathrm{C}$ & $\mathrm{S}$ & $\mathrm{c}$ & $\mathrm{s}$ \\
\hline 0 & 1 & 0 & 0 & 4 & & $\Lambda$ & & 4 & $\mathrm{D}$ & $\mathrm{T}$ & $\mathrm{d}$ & $\mathrm{t}$ \\
\hline 0 & 1 & 0 & 1 & 5 & & $\Omega$ & $\%$ & 5 & $E$ & $\mathrm{U}$ & $\mathrm{e}$ & $\mathrm{u}$ \\
\hline 0 & 1 & 1 & 0 & 6 & & $\Pi$ & $\&$ & 6 & $\mathrm{~F}$ & $\mathrm{~V}$ & $\mathrm{f}$ & $\mathrm{V}$ \\
\hline 0 & 1 & 1 & 1 & 7 & & $\Psi$ & 6 & 7 & $\mathrm{G}$ & W & $\mathrm{g}$ & w \\
\hline 1 & 0 & 0 & 0 & 8 & & $\Sigma$ & ( & 8 & $\mathrm{H}$ & $\mathrm{X}$ & $\mathrm{h}$ & $\mathrm{X}$ \\
\hline 1 & 0 & 0 & 1 & 9 & & $\Theta$ & ) & 9 & I & $\mathrm{Y}$ & $\mathrm{i}$ & $\mathrm{y}$ \\
\hline 1 & 0 & 1 & 0 & 10 & LF & $\Xi$ & $*$ & $:$ & $\mathrm{J}$ & $\mathrm{Z}$ & $\mathrm{j}$ & $\mathrm{z}$ \\
\hline 1 & 0 & 1 & 1 & 11 & & & + & ; & $\mathrm{K}$ & $\mathrm{A}$ & $\mathrm{k}$ & $\mathrm{a}$ \\
\hline 1 & 1 & 0 & 0 & 12 & & & , & $<$ & $\mathrm{L}$ & $\mathrm{U}$ & 1 & $\mathrm{O}$ \\
\hline 1 & 1 & 0 & 1 & 13 & CR & & - & $=$ & M & & $\mathrm{m}$ & \\
\hline 1 & 1 & 1 & 0 & 14 & & $\beta$ & . & $>$ & $\mathrm{N}$ & $\mathrm{U}$ & $\mathrm{n}$ & $\mathrm{u}$ \\
\hline 1 & 1 & 1 & 1 & 15 & & & 1 & $?$ & $\mathrm{O}$ & & 0 & \\
\hline
\end{tabular}

So that, in conversion 7-bit code of word "hello" it will convert into bellow,

\begin{tabular}{|c|c|c|c|c|c|c|c|}
\hline Bit & $\mathbf{7}$ & $\mathbf{6}$ & $\mathbf{5}$ & $\mathbf{4}$ & $\mathbf{3}$ & $\mathbf{2}$ & $\mathbf{1}$ \\
\hline $\mathrm{h}$ & 1 & 1 & 0 & 1 & 0 & 0 & 0 \\
\hline $\mathrm{e}$ & 1 & 1 & 0 & 0 & 1 & 0 & 1 \\
\hline $\mathrm{l}$ & 1 & 1 & 0 & 1 & 1 & 0 & 0 \\
\hline $\mathrm{l}$ & 1 & 1 & 0 & 1 & 1 & 0 & 0 \\
\hline $\mathrm{o}$ & 1 & 1 & 0 & 1 & 1 & 1 & 1 \\
\hline
\end{tabular}

And then change the 7-bit into 8-bit as shown below,

\begin{tabular}{|c|c|c|c|c|}
\hline & o & 1 & $\mathrm{e}$ & $\mathrm{h}$ \\
\hline $00000 \quad 110$ & $1111 \quad 1101$ & $100 \quad 11011$ & $00 \quad 110010$ & 11101000 \\
\hline 0 & D & B & 2 & $\mathrm{E}$ \\
\hline
\end{tabular}

Because the total of 7-bit multiply by 5 characters is 35-bit, whereas the number needed of 8-bit multiply by 5 characters is 40-bit, so it needs a 5-bit dummy with fulfilling with zero (' 0 '). Every 1 byte or 8 bits represents a hexadecimal pair which is of 4 bit represents a hexadecimal number obviously $2^{4}=16$. So the word "hello", its conversion result is E8329BFD06.

\section{Methodology}

The GSM mobile phone for control has been implemented to control a direct current (DC) motor [5], intelligent home security [6], irrigation system [7], etc. This paper uses AT89S51 microcontroller from the microcontroller family of MCS-51 having 4-Kbyte Flash programmable erasable read-only memory (PEROM) which is packaged within 40 pins. This microcontroller is using a direct current (DC) power supply of 5 Volt. The AT89S51 microcontroller has an on-chip which is utilized as a clock generator to the central processing unit (CPU) or also known as the core. The clock generator in this paper is using a crystal resonator of $11.0592 \mathrm{MHz}$ which is connected to the pins of xtal1 (pin 19) and xtal2 (pin 18) with two grounded capacitors of $33 \mathrm{pF}$. So the time, $\tau$, for executing the program instruction program can be written using (1).

$\tau=\frac{\eta}{\xi}$

Where $\eta$ is a cycle number and $\xi$ is a frequency within $\operatorname{Hertz}(\mathrm{Hz})$. So if the frequency of the clock used is $11.0592 \mathrm{MHz}$, it will have $0.09 \times \eta \mu \mathrm{s}$. The mini development system schematic of this microcontroller is shown in Figure 2.

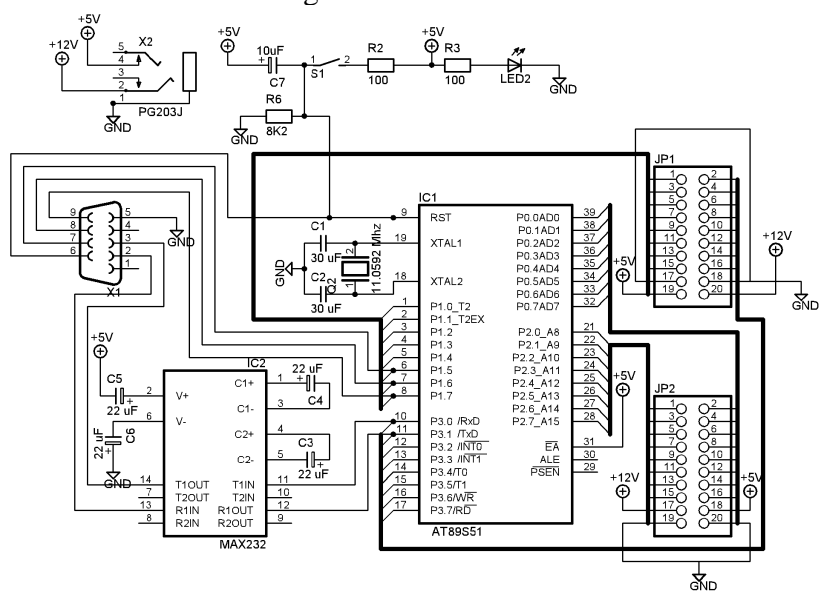

Fig. 2: Schematic of a mini development system

This mini development system as shown in Figure 2 is also connected to the RS232 circuit by implementing an integrated circuit (IC) of MAX232. The RS232 communication is an asynchronous meaning that the clock signal is not sent along with the data. This paper has implemented the RS232 with the level set of the $8 \mathrm{~N} 1$ data structure. The $8 \mathrm{~N} 1$ means that there are 8 data bits, No parity bit, and 1 stop bit. For communicating between the microcontroller mini development system and the mobile phone, it implements a baud rate of 19200 bits per second (bps). The communication with the serial ports needs to be checked to know what kind of data form that has been sent so it needs another device to monitor. To monitor this communication, it applies a wiring connection as shown in Figure 4. 


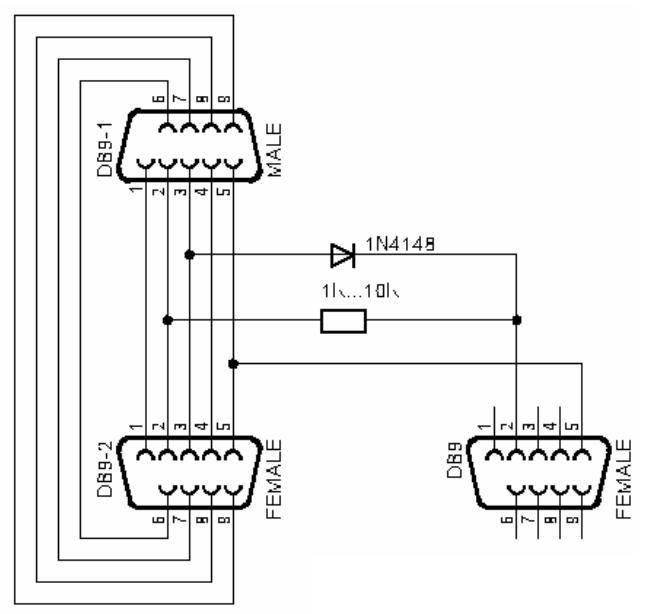

Fig. 3: Schematic of the monitoring device

The connector of DB9-1 is connected to the data cable of the mobile phone and the connector of DB9-2 is connected to the microcontroller mini development system, whereas the connector of DB9 is connected to the computer. To make monitoring, the computer should be installed a program application of serial watcher as shown in Figure 4.

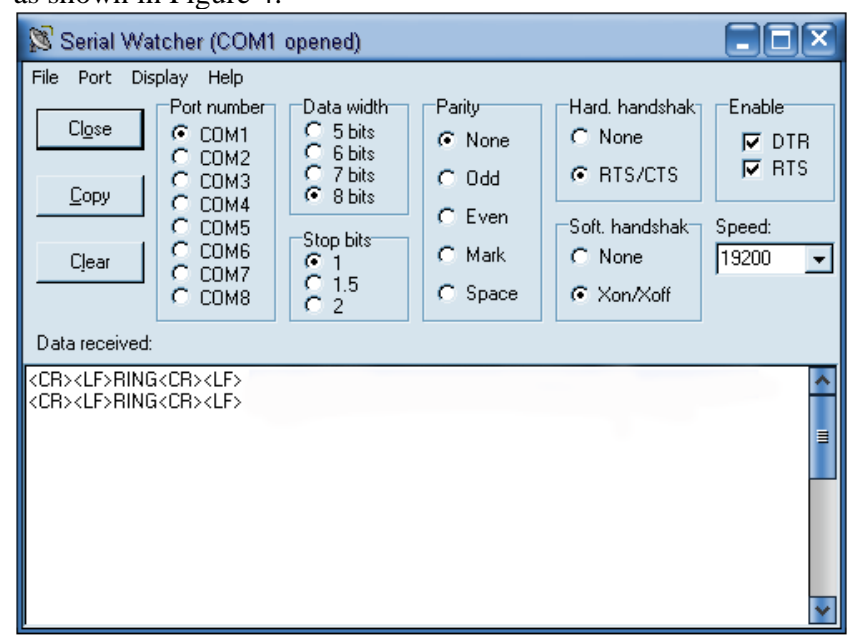

Fig. 4: Serial Watcher

\section{Result and Discussion}

The first thing to do in programming this microcontroller is to synchronize the baud rate to match the baud rate on the mobile phone so that communication occurs. The baud rate program for this microcontroller is configured as $19200 \mathrm{bps}$. After it sets, thus enables the serial interruption and fill the register $\mathrm{R} 0$ with $00 \mathrm{H}$. In this case, to detect the missed call signal it could be formed as Figure 4. The signal missed call will be detected as American standard code for information interchange (ASCII) code as $\langle\mathrm{CR}\rangle\langle\mathrm{LF}\rangle \mathrm{RING}\langle\mathrm{CR}\rangle\langle\mathrm{LF}\rangle$. For the reason of flexibility in programming, to count the number of the missed call tone it is using $\langle\mathrm{CR}\rangle\langle\mathrm{LF}\rangle \mathrm{R}$ only as a reference to be detected and programmed to the microcontroller. The result obtained after execution, the counting of the missed call can be counted well that is known from the program to control the DC motor (see Figure 5). For taking control of the DC motor turns on, it can be activated using two times ring that is generated from the missed call tone and to turn the DC motor off can be generated four times of missed call tone.

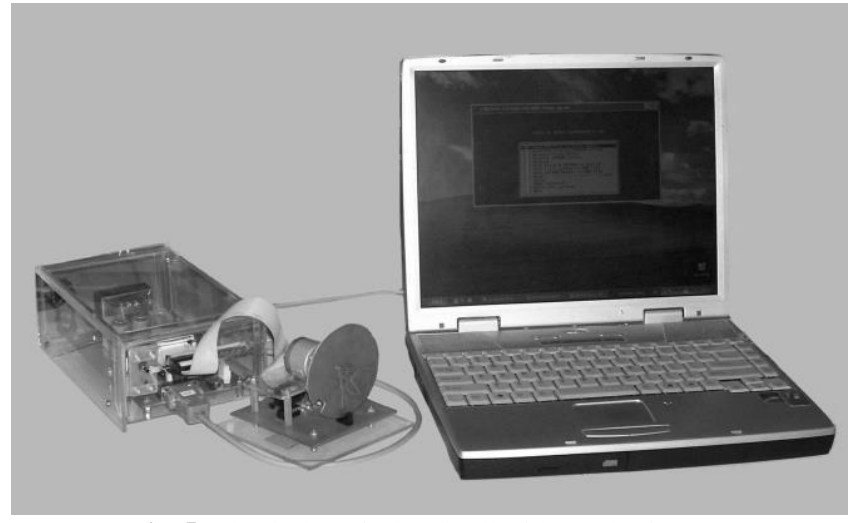

Fig. 5: The device of missed call with monitoring test

The serial watcher software is applied to monitor each instruction given by the microcontroller and the response data of the mobile phone. The interruption signal is always checked until the value of register R0 is changing into ' 1 '. If this register value has been set into ' 1 ' so it will make a delay about 1.5 minutes and then turn the serial interrupt off. When in the delay time, the count program of the missed call will be enabled to count the tone. Since every provider has a different time to end the connection of the telephone so the microcontroller has been programmed for 1.5 minutes. The process of monitoring this connection can be shown in Figure 6.

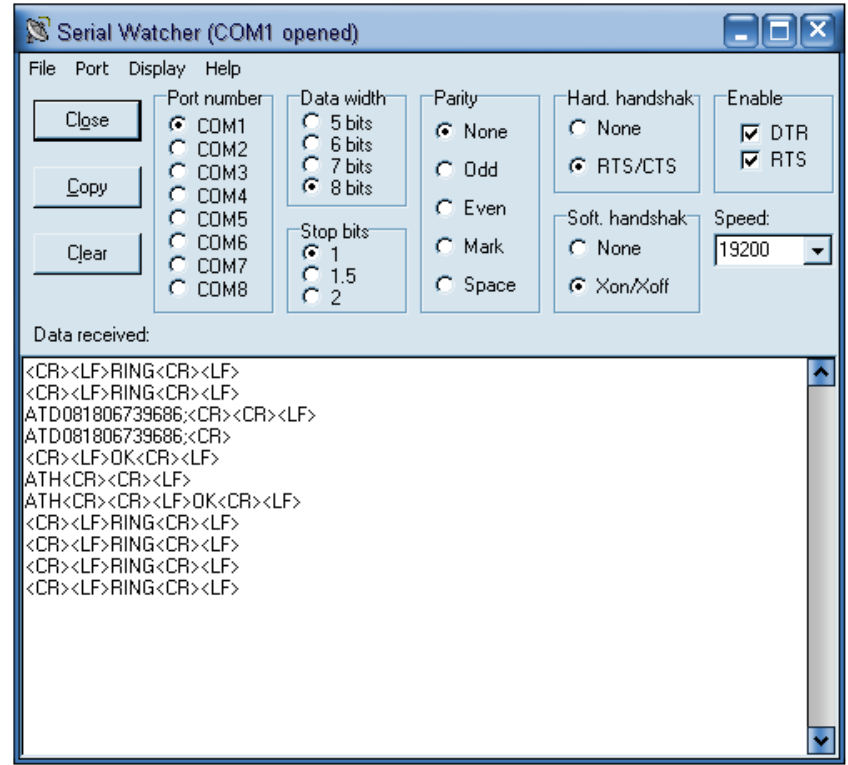

Fig. 6: Conversation monitoring of the devices

From Figure 6, it shows that the conversation monitoring has been done by both devices. This conversation means that after it has detected the tone of the missed call twice, the microcontroller will send the response to the mobile phone to call the other mobile phone number using a command of ATD, if the mobile phone has accepted the instruction, it will send "OK" to the microcontroller. Then the microcontroller will send an instruction to make a mobile phone is hooked. This program is intended to convince the other mobile phone number that the calls made are correct by making a call back to that mobile phone number for a few seconds until the connection will be turned off by hooking the mobile phone. For the purpose of using the password, it can be used that the missed call tone that is enumerated is correct and the mobile phone will wait for the next count of missed call tone. This program is also included to turn all interruptions off when the count of the tones of missed call has a wrong counting so the password entry will be locked until it is restarted so the program will normally run again. 


\section{Conclusion}

A device has been designed and implemented to detect a missed call and count the number of tones produced to function as passwords and control devices. The thing that needs to be considered in the utilization of this device is remembering the counts done when doing a missed call. If it is unable to remember and cause an error in entering the missed call tone count, it will cause the device to turn off all serial interruptions that appear, so that communication can no longer be performed.

\section{Acknowledgment}

Thank you for my supervisor who has guided me, Prof. Dr. Jazi Eko Istiyanto. From his hands and thought, a lot of research that I can do.

\section{References}

[1] Wibowo FW, "A dynamic intelligent control analysis on the wireless smart machine environments in the industry 4.0", Proceedings of the 2018 international seminar on research of information technology and intelligent systems (ISRITI), (2018), pp: 389-393.

[2] Donner J, "The rules of beeping: exchanging messages via intentional "missed calls" on mobile phones", Journal of ComputerMediated Communication, Vol. 13, (2008), pp: 1-22. DOI: 10.1111/j.1083-6101.2007.00383.x

[3] Fernández-Ardèvol M, "Missed calls: Barcelona and Los Angeles compared", Proceedings of the Technology \& Emerging Media Track - Annual Conference of the Canadian Communication Association, (2012), pp: 1-14

[4] Maqbool S \& Lone SA, "Monitoring system using GSM", International Journal of Computer Applications, Vol. 117, No. 10, (2015), pp: $28-31$.

[5] Istiyanto JE \& Wibowo FW, "A DC Motor Control Based-on Cellular Phone", Proceedings of $2^{\text {nd }}$ Jogja International Physics Conference, (2007), pp. EI072-EI075.

[6] Eseosa O \& Promise E, "GSM based intelligent home security system for intrusion detection", International Journal of Engineering and Technology, Vol. 4, No. 10, (2014), pp: 595-605.

[7] Sangme PB, Khatal RB, Patil OM \& Patil AG, "GSM based motor control for irrigation system", International Journal of Innovative Research in Computer and Communication Engineering, Vol. 6, Issue 3 , (2018), pp: 2138-2142. DOI: 10.15680/IJIRCCE.2018.0603064 